\title{
Downregulation of $\gamma$-catenin inhibits CML cell growth and potentiates the response of CML cells to imatinib through $\beta$-catenin inhibition
}

\author{
CHANG-CHUN NIU ${ }^{1,2}$, CHEN ZHAO $^{1}$, ZHEN-DONG YANG $^{2}$, XIAO-LI ZHANG ${ }^{1}$, WEI-RU WU ${ }^{1}$, \\ JING PAN $^{1}$, CHEN ZHAO $^{3}$, ZHI-QIANG LI ${ }^{1}$, WEI DING ${ }^{1}$, ZHONG YANG $^{1}$ and WEI-KE SI ${ }^{1}$ \\ ${ }^{1}$ Department of Clinical Hematology, The Third Military Medical University, Chongqing 400038; \\ ${ }^{2}$ Department of Clinical Laboratory, The 154th Central Hospital, Xinyang, Henan 464000; ${ }^{3}$ Department of Orthopedics, \\ The First Affiliated Hospital, Chongqing Medical University, Chongqing 400038, P.R. China
}

Received September 8, 2012; Accepted November 9, 2012

DOI: $10.3892 /$ ijmm.2012.1207

\begin{abstract}
. $\gamma$-catenin plays different roles in different types of tumors, and its role in chronic myeloid leukemia (CML) cells has yet to be identified. In our study, two CML cell lines (K562, KU812) had higher $\gamma$-catenin expression levels compared to five types of BCR-ABL-negative leukemia cells. Knockdown of the expression of BCR-ABL resulted in downregulation of $\gamma$-catenin. Furthermore, downregulation of $\gamma$-catenin by siRNA inhibited the proliferation and colony formation of CML cells and the expression of the c-Myc and cyclin D1 genes; downregulation of $\gamma$-catenin also potentiated the effects of imatinib (inhibiting CML cell proliferation and inducing apoptosis) and suppressed the anti-apoptotic genes Bcl-xL and survivin. We also showed that downregulation of $\gamma$-catenin suppressed the phosphorylation of STAT5, promoted the phosphorylation of $\beta$-catenin and reduced the translocation of $\beta$-catenin into the nucleus, although there were no effects on the total level of $\beta$-catenin expression in the whole cells. Furthermore, downregulation of $\gamma$-catenin was found to promote glycogen synthase kinase-3 $\beta$ (GSK3 $\beta$ ) and inhibit its phosphorylation. Collectively, our results suggest that $\gamma$-catenin is an oncogene protein in CML that can be regulated by BCR-ABL and that suppression of $\gamma$-catenin inhibits CML cell growth and potentiates the effects of imatinib on CML cells through inhibition of the activation of STAT5 and suppression of $\beta$-catenin by activating GSK3 $\beta$.
\end{abstract}

\section{Introduction}

$\gamma$-catenin (plakoglobin), a member of the Armadillo proteins (1), plays important roles in cell adhesion with $\alpha$-catenin and

Correspondence to: Dr Wei-Ke Si or Dr Zhong Yang, Department of Clinical Hematology, The Third Military Medical University, Chongqing 400038, P.R. China

E-mail: weikesi2004@hotmail.com

E-mail: yangzhong1999@163.com

Key words: $\gamma$-catenin, chronic myeloid leukemia, BCR-ABL, $\beta$-catenin $\beta$-catenin (2), is involved in Wnt signaling (3), and is translocated into the nucleus and binds LEF1, but is inefficient in forming a complex with DNA (4), and even inhibits the transcriptional activity of the TCF4 complex (5). Despite the homology and the similar structure of $\gamma$-catenin and $\beta$-catenin, the differences between them are rather distinct (6); $\beta$-cateninnull mice and $\gamma$-catenin-null mice have different phenotypes (7). $\beta$-catenin is regarded as an oncogenic protein, while there are different proposed roles for $\gamma$-catenin for different types of tumors. In renal carcinoma cell KTCTL 60 cells (8), squamous carcinoma cell SCC9 cells (9), lung cancer (10), mammary carcinoma MCF-7 cells (11), and bladder carcinomas (12), $\gamma$-catenin acts as a tumor suppressor. By contrast, $\gamma$-catenin acts as an oncogenic factor in human colonic carcinoma HTC116 cells (13), and $\gamma$-catenin can promote the transformation of RK3E cells (14).

In chronic myeloid leukemia (CML), the reciprocal translocation of chromosomes 9 and 22 forms the Philadelphia chromosome, which results in the expression of a fused BCR-ABL protein. The BCR-ABL protein activates a series of proteins to promote cell survival and cell growth $(15,16)$. Previous studies have shown that $\gamma$-catenin can be regulated by the acute myeloid leukemia (AML) fused protein AML1-ETO, PML-retinoic acid receptor- $\alpha(\operatorname{RAR} \alpha)$ and PLZF-RAR $\alpha(17)$, but the influence of BCR-ABL on the expression of $\gamma$-catenin remains unclear. It has been shown that $\beta$-catenin is crucial for CML cells (18), and $\beta$-catenin siRNA sensitizes CML cells to imatinib (19). Although $\gamma$-catenin and $\beta$-catenin belong to the same family, the role of $\gamma$-catenin in CML is elusive. In a study by Kim et al (20), CML patients in the accelerated phase and blast crisis (AP/BC) stages had significantly increased levels of $\gamma$-catenin, suggesting that $\gamma$-catenin may also play a crucial role in CML cells.

In this study, we showed that two BCR-ABL positive CML cell types (K562 cells and KU812 cells) had higher expression levels of $\gamma$-catenin compared to five BCR-ABL-negative leukemia cells. Suppressing the expression of BCR-ABL with siRNA resulted in decreased $\gamma$-catenin expression. Furthermore, suppression of $\gamma$-catenin by siRNA inhibited proliferation, colony formation and the $\beta$-catenin target genes 
c-Myc and cyclin D1. Suppression of $\gamma$-catenin also potentiated the effects of imatinib on CML cells and suppressed the expression of Bcl-xL and survivin (a $\beta$-catenin target gene). Furthermore, suppression of $\gamma$-catenin suppressed the activation of STAT5 and inhibited $\beta$-catenin by promoting its phosphorylation and inhibiting its translocation into the nucleus. Finally, downregulation of $\gamma$-catenin resulted in the increased total glycogen synthase kinase-3 $\beta$ (GSK3 $\beta$ ) and suppression of phospho-GSK3 $\beta$. This study helps elucidate the role of $\gamma$-catenin in CML cells and provides a marker or strategy for CML treatment.

\section{Materials and methods}

Cells and reagents. The cells were purchased from the Shanghai Cell Bank (Shanghai, China) and were maintained in a $37^{\circ} \mathrm{C} / 5 \% \mathrm{CO}_{2}$ atmosphere. IMDM and DMEM medium were purchased from Hyclone, and fetal bovine serum (FBS) was purchased from Gibco. The human CML cell lines, K562 and KU812, were maintained in DMEM or IMDM medium supplemented with 10 or $20 \%$ FBS, respectively. Human leukemia cells, Jurkat cells, U937 cells, CEM cells and Kasumi cells were maintained in RPMI-1640 medium supplemented with $10 \%$ FBS, and HL-60 cells were maintained in IMDM medium supplemented with $20 \%$ FBS. Human embryonic kidney cells HEK293 cells were maintained in DMEM medium supplemented with $10 \%$ FBS. Imatinib, a BCR-ABL inhibitor, purchased from Selleck Chemicals, was dissolved in DMSO (Sigma-Aldrich).

Stable cell line construction. The pSES-hus plasmid was used to construct the siRNA retrovirus. The pSES-hus plasmid was digested with the $S f i$ I restriction endonuclease and ligated with annealed DNA chains for siRNA. The BCR-ABL (target sequence, 5'-GCAGAGTTCAAAAGCCCTT-3') and $\gamma$-catenin (target sequence, 5'-GCTGATCATCCTGGCCAA-3') genes were the targets for the siRNA. A randomized sequence that did not target any gene was used as an siRNA control.

Subsequently, pSES-hus-siBCR-ABL and pSES-hus- $\gamma$ catenin were used to package the retrovirus with pCL-ampho with co-transfection into HEK 293 cells. K562 and KU812 cells were infected with the retrovirus. Stable cell lines were obtained through Blasticidin (Invitrogen) selection. The cells infected with the BCR-ABL siRNA retrovirus were labeled K562-siBCR-ABL and KU812-siBCR-ABL, and the cells infected with the $\gamma$-catenin siRNA retrovirus were labeled K562-si $\gamma$-catenin and KU812-si $\gamma$-catenin. The siRNA control cells were labeled K562-siControl and KU812-siControl cells.

Western blotting, co-immunoprecipitation (Co-IP), and nuclear protein and cytoplasmic protein extraction. Western blot analysis was carried out as previously described (21), and the entire process was performed using the Bio-Rad system. The anti-c-Abl, anti-c-Myc, anti-cyclin D1, anti-survivin, anti-Bcl-xL, anti-phospho-STAT5, anti- $\beta$-catenin, antiphospho- $\beta$-catenin, anti-GSK3 $\beta$, and anti-phospho-GSK3 $\beta$ antibodies were obtained from Cell Signaling Technology. The anti- $\beta$-actin antibody, mouse IgG and rabbit IgG were obtained from Santa Cruz Biotechnology, Inc., while the anti$\gamma$-catenin antibody (mouse antibody) was from Abcam.
Co-IP was carried out with a Pierce Co-IP kit. A Nuclear Protein and Cytoplasmic Protein Extraction kit (Beyotime, China) was used to extract protein from the cell nucleus or cytoplasm. An anti-Histone H1 (Santa Cruz Biotechnology, Inc.) antibody was used as a loading control for the proteins in the nucleus.

Apoptosis analysis. After washing the cells three times with ice-cold phosphate-buffered saline (PBS), they were resuspended in binding buffer, stained with Annexin V-APC (KeyGentec, China) and propidium iodide (PI; Sigma-Aldrich), and analyzed by flow cytometry (BD Biosciences).

Cell proliferation analysis and colony formation assay. Cell proliferation analysis was conducted with a CCK-8 kit (Dojindo, Japan) according to the manufacturer's instructions.

The colony formation assay was performed as follows: the cells $\left(2 \times 10^{3}\right.$ cells/well $)$ were plated in methylcellulose (1\% final concentration; Sigma-Aldrich) semi-solid medium. Seven (K562 cells) or 12 days (KU812 cells) later, the colonies containing $>40$ cells each were counted.

Statistical analysis. Statistical tests were performed using the Student's t-test with SPSS software. A P-value $<0.05$ was considered to indicate statistically significant differences. The tests were conducted three times, and the results are presented as the means $\pm \mathrm{SD}$.

\section{Results}

Downregulation of $B C R-A B L$ suppresses $\gamma$-catenin, but $\gamma$-catenin cannot bind $B C R-A B L$. Kim et al (20) found elevated levels of $\gamma$-catenin in AP/BC stage patients. We evaluated the expression of $\gamma$-catenin in leukemia cell lines. K562 and KU812 cells had higher levels of $\gamma$-catenin expression than the BCR-ABL-negative cell lines (Fig. 1A). It suggested that BCR-ABL regulates the expression of $\gamma$-catenin. To observe the effects of BCR-ABL on the expression of $\gamma$-catenin, we constructed CML cell lines with stable BCR-ABL siRNA expression: K562-siBCR-ABL and KU812-siBCR-ABL cells (Fig. 1A). We found that K562-siBCR-ABL cells and KU812siBCR-ABL cells had decreased levels of $\gamma$-catenin compared to control cells (Fig. 1B).

To determine whether BCR-ABL regulates $\gamma$-catenin by directly binding $\gamma$-catenin, we performed a Co-IP assay. The results showed that $\gamma$-catenin protein does not bind the BCR-ABL protein (Fig. 1C).

Downregulation of $\gamma$-catenin inhibits the proliferation and colony formation of CML cells. To study the roles of $\gamma$-catenin in CML cells, we constructed the following CML cells with downregulation of $\gamma$-catenin: K562-si $\gamma$-catenin cells and KU812-si $\gamma$-catenin cells.

After the cells $\left(0.5 \times 10^{5} / \mathrm{ml}\right)$ were plated on 96 -well plates, their proliferation was monitored at different time points. As shown in the proliferation curves, the proliferation rate of K562-si $\gamma$-catenin cells was lower than that of K562-siControl cells, and the proliferation rate of KU812-si $\gamma$-catenin cells was lower than that of KU812-siControl cells (Fig. 2A and B). The colony formation assay showed that the $\gamma$-catenin siRNA 
A

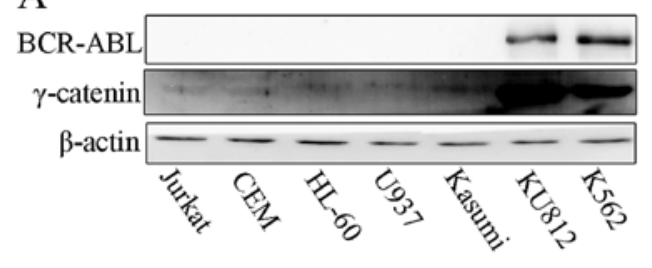

B

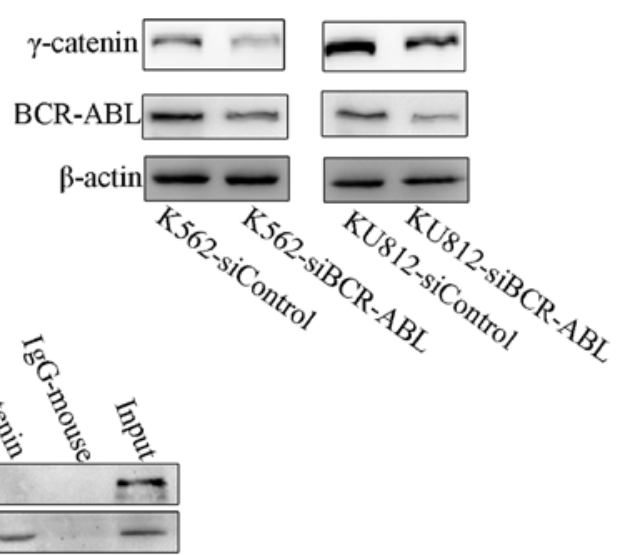

Figure 1. $\gamma$-catenin is regulated by BCR-ABL in CML cells. (A) Western blotting for $\gamma$-catenin in the leukemia cells. (B) Western blotting for $\gamma$-catenin in the BCR-ABL siRNA CML cells or the control cells; $\beta$-actin was used as the loading control. (C) Co-immunoprecipitation (Co-IP) analysis for the physical interaction of the BCR-ABL and $\gamma$-catenin proteins in K562 cells. Input: the cell lysates were used as positive control.
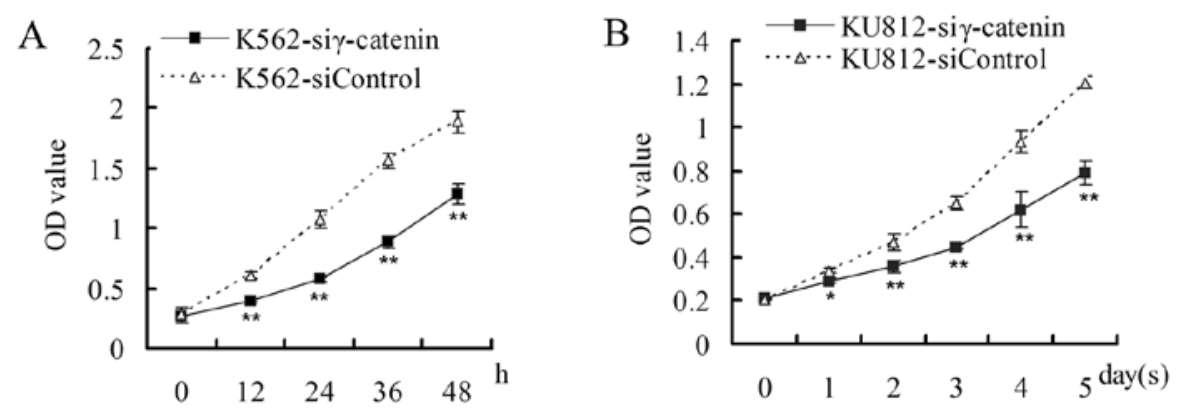

$\mathrm{C}$

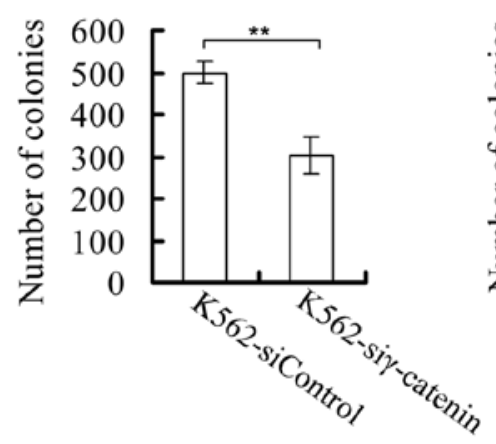

$\mathrm{D}$

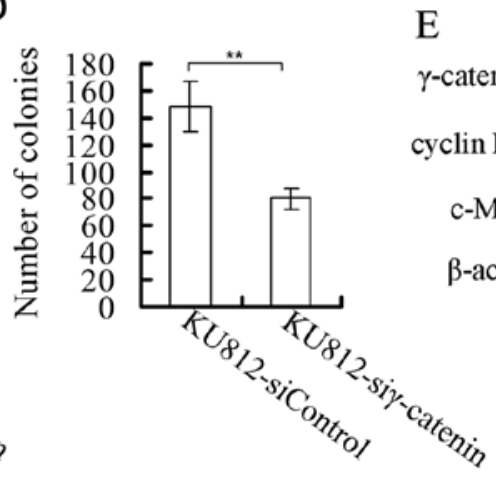

E

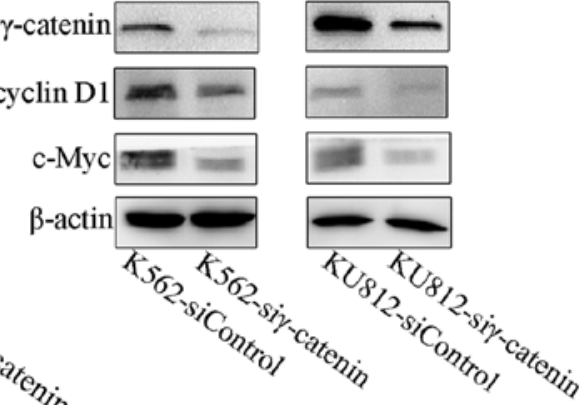

Figure 2. Downregulation of $\gamma$-catenin inhibits the growth and colony formation of CML cells. (A and B) Equal numbers of the $\gamma$-catenin siRNA cells and the control cells were plated on a 96-well plate. The cell proliferation was monitored with the CCK-8 assay at different time points. h, hour. (C and D) Equal numbers of the $\gamma$-catenin siRNA cells and the control cells were plated on a 6-well plate, and the numbers of colonies were counted at different time points. (E) Western blotting for the proteins in the $\gamma$-catenin siRNA cells and the control cells; $\beta$-actin was used as the loading control. $\mathrm{P}<0.05$, ${ }^{* *} \mathrm{P}<0.01$.

CML cells formed fewer colonies than the control cells (Fig. 2C and D).

We also examined the expression of c-Myc and cyclin D1, which are $\beta$-catenin target genes $(22,23)$. The expression levels of c-Myc and cyclin D1 in the $\gamma$-catenin siRNA cells were lower than in the control cells (Fig. 2E).

Downregulation of $\gamma$-catenin potentiates the sensitivity of CML cells to imatinib. We also examined the influence of $\gamma$-catenin on the sensitivity of CML cells to imatinib. To exclude the influence of $\gamma$-catenin on cell proliferation, the proliferation of the treated cells was normalized to cells that were not treated with imatinib. The cells $\left(2 \times 10^{5} / \mathrm{ml}\right)$ were plated in 96-well plates and treated with different concentrations of imatinib for $24 \mathrm{~h}$. Imatinib decreased the proliferation of the K562-si $\gamma$-catenin and KU812-si $\gamma$-catenin cells more substantially compared to the control cells (Fig. 3A and B).

Following treatment with imatinib (K562, $6 \mu \mathrm{mol} / \mathrm{l}$; $\mathrm{KU} 812,0.3 \mu \mathrm{mol} / \mathrm{l})$, the percentages of apoptotic K562-si $\gamma$ catenin and KU812-si $\gamma$-catenin cells were higher than for control cells (Fig. 3C and D).

We then examined the changes in the expression levels of survivin (a $\beta$-catenin target gene) (24) and Bcl-xL and found lower expression levels of these proteins in K562-si $\gamma$ - 

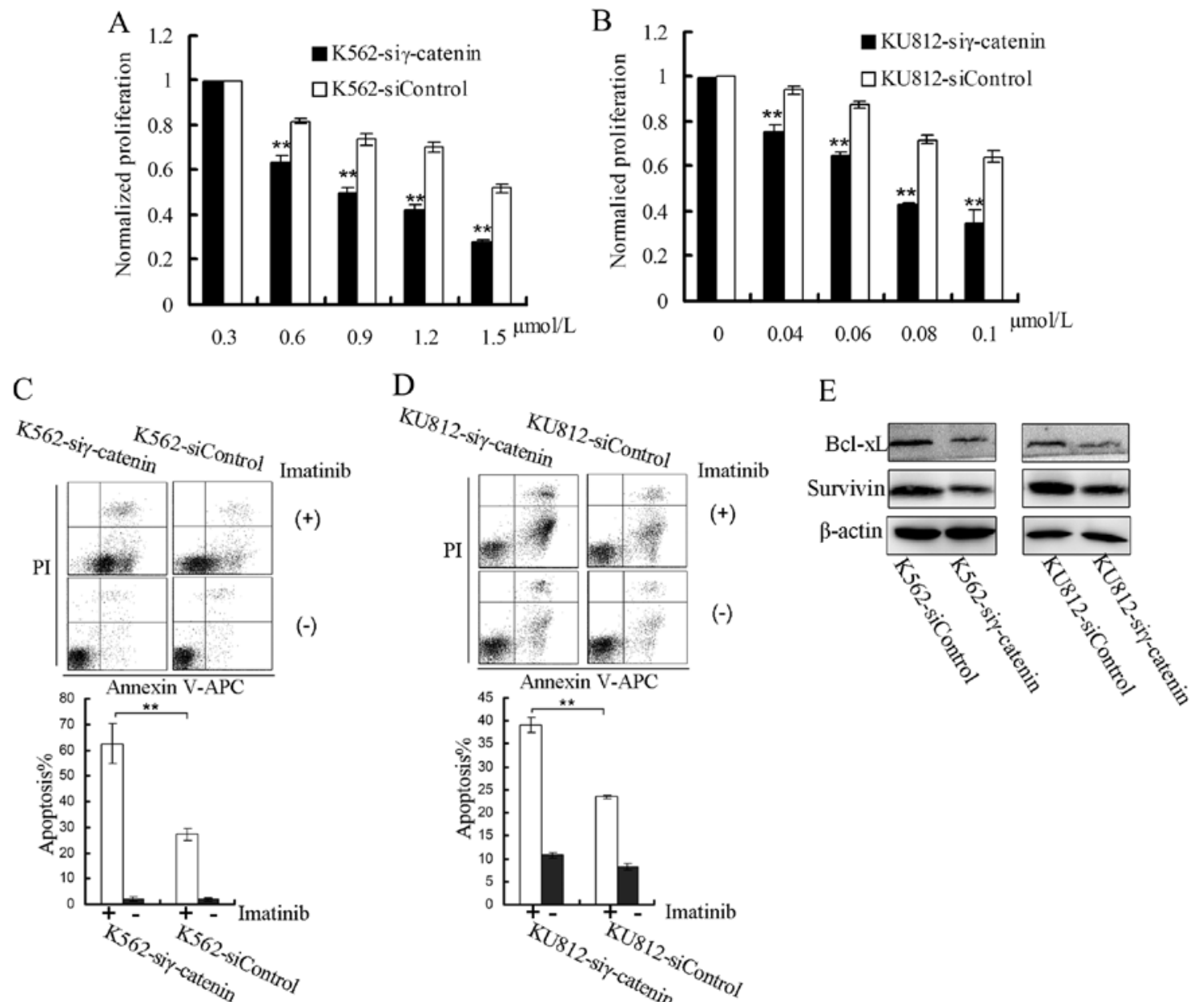

Figure 3. Downregulation of $\gamma$-catenin potentiates the sensitivity of CML cells to imatinib. (A and B) The cells were treated with different concentrations of imatinib for $24 \mathrm{~h}$, and the cell proliferation was monitored with the CCK-8 assay. The cell proliferation was normalized to the proliferation of the cells that did not receive imatinib treatment. (C and D) The cells were treated with imatinib for $18 \mathrm{~h}$, and then the cells were stained with Annexin V-APC/PI and analyzed by flow cytometry. The apoptotic cells are shown in the lower right quadrant, and the graphs represent the percentages of apoptotic cells. (E) Western blotting for the proteins in the $\gamma$-catenin siRNA cells and the control cells; $\beta$-actin was used as the loading control. ${ }^{* * *} \mathrm{P}<0.01$.

catenin and KU812-si $\gamma$-catenin cells than in the control cells (Fig. 3E).

Downregulation of $\gamma$-catenin suppresses STAT5 phosphorylation, promotes $\beta$-catenin phosphorylation and inhibits $\beta$-catenin translocation into the nucleus. STAT5 has been shown to be activated by BCR-ABL, to be involved in the signaling of BCR-ABL, and to be important for growth and apoptosis resistance (15). Bcl-xL and the cyclin D1 have been shown to be the targets of STAT5 in BCR-ABL-transformed cells (25). The effects of siRNA against $\gamma$-catenin on the activation of STAT5 were also evaluated. We found that the phospho-STAT5 level was lower in the $\gamma$-catenin siRNA CML cells than in the control cells (Fig. 4A).

As shown above, downregulation of $\gamma$-catenin reduced the expression of c-Myc (22), cyclin D1 (23) and survivin (24). Since these proteins are downstream target genes of $\beta$-catenin, we posited that $\gamma$-catenin influences $\beta$-catenin. There was no change in the expression of $\beta$-catenin in $\gamma$-catenin siRNA CML cells (Fig. 4A). However, there was an increased level of phospho- $\beta$-catenin in $\gamma$-catenin siRNA CML cells (Fig. 4A), a decreased $\beta$-catenin level in the nucleus, and an increased $\beta$-catenin level in the cytoplasm of the $\gamma$-catenin siRNA CML cells (Fig. 4B).

Downregulation of $\gamma$-catenin promotes GSK3 $\beta$ and suppression of phospho-GSK $3 \beta$. Due to the regulation of $\beta$-catenin by GSK3 3 (26), we investigated whether GSK3 $\beta$ was involved in the $\gamma$-catenin regulation of $\beta$-catenin. We found that $\gamma$-catenin downregulation leads to downregulation of phospho-GSK3 $\beta$ and upregulation of total GSK3 $\beta$, compared with the control cells (Fig. 4C).

\section{Discussion}

Our study helps elucidate the roles of $\gamma$-catenin in CML cells. $\gamma$-catenin was regulated by the BCR-ABL fused protein, and downregulation of $\gamma$-catenin had an anti-leukemia effect through the inhibition of $\beta$-catenin.

It was previously reported that $\gamma$-catenin expression is amplified in the CML cells of AP/BC stage patients (20) and that BCR-ABL has particularly increased levels in BC stage patients (27). In this study, two CML cells expressed higher levels of $\gamma$-catenin than BCR-ABL-negative leukemia cells. 


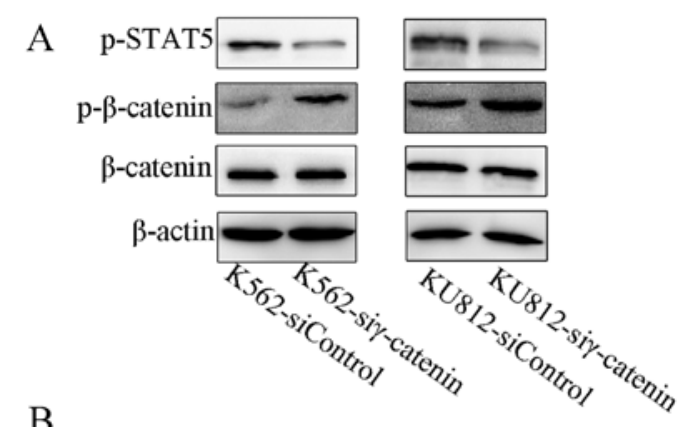

B
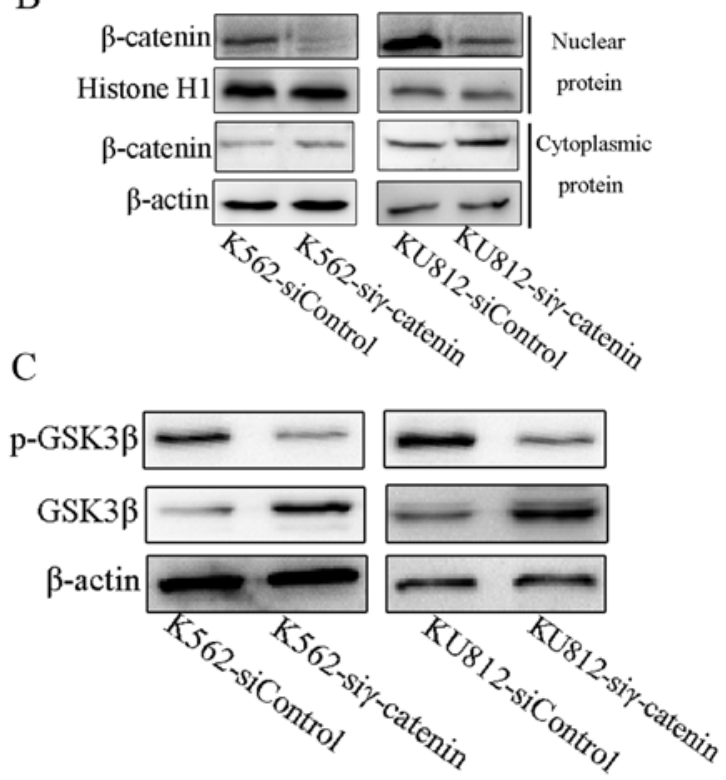

Figure 4. Downregulation of $\gamma$-catenin suppresses phospho-STAT5, inhibit $\beta$-catenin, and promoted GSK3 $\beta$. (A) Western blotting for phospho-STAT5 in the $\gamma$-catenin siRNA CML cells or the control cells; western blotting for $\beta$-catenin in the $\gamma$-catenin siRNA CML cells or the control cells; $\beta$-actin was used as the loading control. (B) Western blotting for $\beta$-catenin in the cell nucleus or cell plasma; histone H1 was used as the loading control for the nuclear protein, and $\beta$-actin was used as the loading control for the cytoplasmic protein. (C) Western blotting for GSK3 $\beta$ in the $\gamma$-catenin siRNA CML cells or the control cells; $\beta$-actin was used as the loading control. p, phospho.

We hypothesized that BCR-ABL can regulate $\gamma$-catenin. To test our hypothesis, we used siRNA to knock down BCR-ABL expression, and found that $\gamma$-catenin is indeed regulated by BCR-ABL. Additionally, it was reported that BCR-ABL stabilizes $\beta$-catenin through binding $\beta$-catenin and its tyrosine phosphorylating $\beta$-catenin (19); thus, we addressed whether BCR-ABL also binds $\gamma$-catenin. However, a Co-IP assay showed that $\gamma$-catenin does not bind BCR-ABL, suggesting that $\mathrm{BCR}-\mathrm{ABL}$ regulates $\gamma$-catenin in an indirect way, which is different from the interaction between BCR-ABL and $\beta$-catenin. However, although there are lower levels of $\gamma$-catenin in the 5 BCR-ABL-negative leukemia cell lines, high levels of $\gamma$-catenin may still exist in the other types of leukemia. In fact, $\gamma$-catenin has been reported to contribute to the signaling pathway of AML translocation products (17).

Our study also showed that the suppression of $\gamma$-catenin resulted in the inhibition of CML cell proliferation and transformation as well as the inhibition of c-Myc and cyclin D1, the target genes of $\beta$-catenin. c-Myc plays important roles in cell proliferation and in the transformation of BCR-ABL-positive cells (28), and cyclin D1 also contributes to BCR-ABL- mediated transformation $(25,29)$. c-Myc has been reported to be suppressed (30) or enhanced (13) by $\gamma$-catenin. In our study, downregulation of $\gamma$-catenin suppressed the expression of c-Myc.

Some signaling proteins influence the effects of imatinib on CML cells (31). In this study, we showed that downregulation of $\gamma$-catenin potentiates the effects of imatinib on CML cells. Based on the report that the disruption of survivin can sensitize CML cells to imatinib (32), the report that Bcl-xL is an apoptosis resistant factor in CML cells (33), and our result that downregulation of $\gamma$-catenin suppressed survivin and Bcl-xL, we speculate that the survivin and Bcl-xL suppression is the mechanism by which downregulation of $\gamma$-catenin sensitizes CML cells to imatinib. However, Dusek et al (34) found that $\gamma$-catenin suppresses the expression of Bcl-xL in keratinocytes, but these differences may be cell-type specific.

It has been reported that $\mathrm{Bcl}-\mathrm{xL}$ and cyclin $\mathrm{D} 1$ are regulated by STAT5 in BCR-ABL-transformed cells (25). Our study showed that downregulation of $\gamma$-catenin decreased the levels of phospho-STAT5, which may be a mechanism for the downregulation of $\gamma$-catenin-mediated suppression of Bcl-xL and cyclin D1 in CML cells. There are differing reports on the influence of $\gamma$-catenin on $\beta$-catenin; it has been reported that $\gamma$-catenin suppresses $\beta$-catenin (35) and decreases the binding of $\beta$-catenin and TCF4 (5). However, it has also been reported that $\gamma$-catenin can promote $\beta$-catenin translocation into nucleus and increase the levels of $\beta$-catenin and the $\beta$-catenin-LEF-DNA complex $(4,36)$. The present study showed that downregulation of $\gamma$-catenin had no influence on $\beta$-catenin expression, but could inhibit $\beta$-catenin translocation into the nucleus and suppress $\beta$-catenin-dependent genes expression. This observation is a possible mechanism for the downregulation of $\gamma$-catenin to suppress the proliferation and transformation of CML cells and potentiate the effects of imatinib on CML cells, due to the reports on the roles of $\beta$-catenin $(18,19)$. Additionally, it has been shown, in BCR-ABL transformed cells, that the loss of $\beta$-catenin can reduce the levels of phosphorylated STAT5 (18); thus, $\beta$-catenin inhibition may be the mechanism by which $\gamma$-catenin downregulation suppressed STAT5 activation.

We also found that the suppression of $\beta$-catenin by downregulation of $\gamma$-catenin occurs through the promotion of GSK3 $\beta$ activation. This suggests that $\gamma$-catenin can stabilize $\beta$-catenin by suppressing GSK3$\beta$. It was previously shown that GSK3 $\beta$ regulates $\gamma$-catenin by phosphorylation (37), and, in the present study, we showed that $\gamma$-catenin can regulate GSK3 $\beta$, indicating that $\gamma$-catenin and GSK3 $\beta$ interact and inhibit each other.

Previously, $\gamma$-catenin was considered to play an important role in cell adhesion and development. It is currently thought that $\gamma$-catenin also plays important roles for tumors. Our studies suggest that $\gamma$-catenin functions as an oncogenic protein in CML cells and can be regulated by the BCR-ABL fused protein. This study provides new insight into the BCR-ABL pathways, the roles of $\gamma$-catenin in CML cells, and a potential target for CML treatment.

\section{Acknowledgements}

This study was supported by the National Natural Science Foundation of China and the Major Program of Natural Science Foundation of Chongqing, China. 


\section{References}

1. Peifer M, McCrea PD, Green KJ, Wieschaus E and Gumbiner BM: The vertebrate adhesive junction proteins beta-catenin and plakoglobin and the Drosophila segment polarity gene armadillo form a multigene family with similar properties. J Cell Biol 118: 681-691, 1992.

2. Zhurinsky J, Shtutman M and Ben-Ze'ev A: Plakoglobin and beta-catenin: protein interactions, regulation and biological roles. J Cell Sci 113: 3127-3139, 2000.

3. Barker $\mathrm{N}$ and Clevers $\mathrm{H}$ : Catenins, Wnt signaling and cancer. Bioessays 22: 961-965, 2000.

4. Zhurinsky J, Shtutman M and Ben-Ze'ev A: Differential mechanisms of LEF/TCF family-dependent transcriptional activation by beta-catenin and plakoglobin. Mol Cell Biol 20: 4238-4252, 2000.

5. Miravet S, Piedra J, Miro F, Itarte E, Garcia de Herreros A and Dunach M: The transcriptional factor Tcf- 4 contains different binding sites for beta-catenin and plakoglobin. J Biol Chem 277: 1884-1891, 2002

6. Aktary Z and Pasdar M: Plakoglobin: role in tumorigenesis and metastasis. Int J Cell Biol 2012: 189521, 2012.

7. Sadot E, Simcha I, Iwai K, Ciechanover A, Geiger B and Ben-Ze'ev A: Differential interaction of plakoglobin and betacatenin with the ubiquitin-proteasome system. Oncogene 19 1992-2001, 2000.

8. Simcha I, Geiger B, Yehuda-Levenberg S, Salomon D and Ben-Ze'ev A: Suppression of tumorigenicity by plakoglobin: an augmenting effect of N-cadherin. J Cell Biol 133: 199-209, 1996.

9. Parker HR, Li Z, Sheinin H, Lauzon G and Pasdar M: Plakoglobin induces desmosome formation and epidermoid phenotype in $\mathrm{N}$-cadherin-expressing squamous carcinoma cells deficient in plakoglobin and E-cadherin. Cell Motil Cytoskeleton 40: 87-100, 1998.

10. Winn RA, Bremnes RM, Bemis L, et al: gamma-catenin expression is reduced or absent in a subset of human lung cancers and re-expression inhibits transformed cell growth. Oncogene 21 7497-7506, 2002.

11. Mukhina S, Mertani HC, Guo K, Lee KO, Gluckman PD and Lobie PE: Phenotypic conversion of human mammary carcinoma cells by autocrine human growth hormone. Proc Natl Acad Sci USA 101: 15166-15171, 2004.

12. Rieger-Christ KM, Ng L, Hanley RS, et al: Restoration of plakoglobin expression in bladder carcinoma cell lines suppresses cell migration and tumorigenic potential. Br J Cancer 92: 2153-2159, 2005.

13. Pan H, Gao F, Papageorgis P, Abdolmaleky HM, Faller DV and Thiagalingam S: Aberrant activation of gamma-catenin promotes genomic instability and oncogenic effects during tumor progression. Cancer Biol Ther 6: 1638-1643, 2007.

14. Kolligs FT, Kolligs B, Hajra KM, et al: gamma-catenin is regulated by the APC tumor suppressor and its oncogenic activity is distinct from that of beta-catenin. Genes Dev 14: 1319-1331, 2000 .

15. Hazlehurst LA, Bewry NN, Nair RR and Pinilla-Ibarz J: Signaling networks associated with BCR-ABL-dependent transformation. Cancer Control 16: 100-107, 2009.

16. Quintas-Cardama A and Cortes J: Molecular biology of bcr-abl1positive chronic myeloid leukemia. Blood 113: 1619-1630, 2009.

17. Muller-Tidow C, Steffen B, Cauvet T, et al: Translocation products in acute myeloid leukemia activate the Wnt signaling pathway in hematopoietic cells. Mol Cell Biol 24: 2890-2904 2004.
18. Zhao C, Blum J, Chen A, et al: Loss of beta-catenin impairs the renewal of normal and CML stem cells in vivo. Cancer Cell 12: 528-541, 2007.

19. Coluccia AM, Vacca A, Dunach M, et al: Bcr-Abl stabilizes beta-catenin in chronic myeloid leukemia through its tyrosine phosphorylation. EMBO J 26: 1456-1466, 2007.

20. Kim YM, Ma H, Oehler VG, et al: The gamma catenin/CBP complex maintains survivin transcription in beta-catenin deficient/depleted cancer cells. Curr Cancer Drug Targets 11: 213-225, 2011.

21. Yuan Y, Niu CC, Deng G, et al: The Wnt5a/Ror2 noncanonical signaling pathway inhibits canonical Wnt signaling in K562 cells. Int J Mol Med 27: 63-69, 2011.

22. He TC, Sparks AB, Rago C, et al: Identification of c-MYC as a target of the APC pathway. Science 281: 1509-1512, 1998

23. Shtutman M, Zhurinsky J, Simcha I, et al: The cyclin D1 gene is a target of the beta-catenin/LEF-1 pathway. Proc Natl Acad Sci USA 96: 5522-5527, 1999.

24. Zhang T, Otevrel T, Gao Z, Ehrlich SM, Fields JZ and Boman BM: Evidence that APC regulates survivin expression: a possible mechanism contributing to the stem cell origin of colon cancer. Cancer Res 61: 8664-8667, 2001.

25. de Groot RP, Raaijmakers JA, Lammers JW and Koenderman L: STAT5-dependent cyclinD1 and Bcl-xL expression in Bcr-Abltransformed cells. Mol Cell Biol Res Commun 3: 299-305, 2000.

26. Polakis P: Wnt signaling and cancer. Genes Dev 14: 1837-1851, 2000.

27. Gaiger A, Henn T, Horth E, et al: Increase of bcr-abl chimeric mRNA expression in tumor cells of patients with chronic myeloid leukemia precedes disease progression. Blood 86: 2371-2378, 1995.

28. Sawyers CL, Callahan W and Witte ON: Dominant negative MYC blocks transformation by ABL oncogenes. Cell 70: 901-910, 1992.

29. Afar DE, McLaughlin J, Sherr CJ, Witte ON and Roussel MF: Signaling by ABL oncogenes through cyclin D1. Proc Natl Acad Sci USA 92: 9540-9544, 1995.

30. Williamson L, Raess NA, Caldelari R, et al: Pemphigus vulgaris identifies plakoglobin as key suppressor of c-Myc in the skin. EMBO J 25: 3298-3309, 2006.

31. Diamond JM and Melo JV: Mechanisms of resistance to BCR-ABL kinase inhibitors. Leuk Lymphoma 52 (Suppl 1): S12-S22, 2011

32. Wang Z, Sampath J, Fukuda S and Pelus LM: Disruption of the inhibitor of apoptosis protein survivin sensitizes Bcr-abl-positive cells to STI571-induced apoptosis. Cancer Res 65: 8224-8232, 2005.

33. Amarante-Mendes GP, McGahon AJ, Nishioka WK, Afar DE, Witte ON and Green DR: Bcl-2-independent Bcr-Abl-mediated resistance to apoptosis: protection is correlated with up regulation of Bcl-xL. Oncogene 16: 1383-1390, 1998.

34. Dusek RL, Godsel LM, Chen F, et al: Plakoglobin deficiency protects keratinocytes from apoptosis. J Invest Dermatol 127: 792-801, 2007

35. Salomon D, Sacco PA, Roy SG, et al: Regulation of beta-catenin levels and localization by overexpression of plakoglobin and inhibition of the ubiquitin-proteasome system. J Cell Biol 139: 1325-1335, 1997.

36. Li L, Chapman K, Hu X, Wong A and Pasdar M: Modulation of the oncogenic potential of beta-catenin by the subcellular distribution of plakoglobin. Mol Carcinog 46: 824-838, 2007.

37. Kodama S, Ikeda S, Asahara T, Kishida M and Kikuchi A: Axin directly interacts with plakoglobin and regulates its stability. J Biol Chem 274: 27682-27688, 1999. 